\title{
Implementasi Algoritma Apriori Pada Penyusunan Menu Makanan Rumah Makan Prasmanan
}

\author{
http://dx.doi.org/10.28932/jutisi.v6i2.2742
}

\author{
Asep Budiman Kusdinar ${ }^{\# 1}$, Daris Riyadi ${ }^{\boxplus 2}{ }^{\#}$ Asriyanik $^{\# 3}$ \\ \#Jurusan Teknik Informatika, Universitas Muhammadiyah Sukabumi \\ Jl. R. Syamsudin, SH. No. 50 Kota Sukabumi Jawa Barat \\ ${ }^{1}$ Asep.Budiman.k@gmail.com \\ ${ }^{2}$ Darisriyadi@gmail.com \\ 3asriyanik2630ummi.ac.id
}

\begin{abstract}
A buffet restaurant is a restaurant that provides buffet food that is served directly at the dining table so that customers can order more food according to their needs. This study uses the association rule method which is one of the methods of data mining and a priori algorithms. Data mining is the process of discovering patterns or rules in data, in which the process must be automatic or semi-automatic. Association rules are one of the techniques of data mining that is used to look for relationships between items in a dataset. While the apriori algorithm is a very well-known algorithm for finding high-frequency patterns, this a priori algorithm is a type of association rule in data mining. Highfrequency patterns are patterns of items in the database that have frequencies or support. This high-frequency pattern is used to develop rules and also some other data mining techniques. The composition of the food menu in the Asgar restaurant is now arranged randomly without being prepared on the food menu between one another. The result of this research is to support the composition of the food menu at the Asgar restaurant so that it is easier to take food menu with one another.
\end{abstract}

Keywords- apriori Algorithm; Association rule; Buffet Restaurant; Data Mining.

\section{Pendahuluan}

Rumah makan prasmanan merupakan suatu tempat usaha yang menyediakan berbagai macam makanan rumahan sehari hari dengan penyajian prasmanan atau biasa disebut juga buffet, yaitu di mana pelanggan mengambil sendiri menu makanan yang telah dijejerkan agar pelanggan lebih leluasa dalam mengambil menu makanan sesuai dengan kebutuhan mereka [1].

Salah satu rumah makan yang menggunakan bentuk penyajian prasmanan yaitu Rumah Makan Asgar yang terletak di jalan Sukabumi - Cianjur KM.11 Kabupaten Sukabumi Provinsi Jawa Barat, penyajian prasmanan yang ada di rumah makan ini yaitu menu makanan dijejerkan langsung di meja makan sehingga pelanggan dapat dengan leluasa mengambil sendiri menu yang diinginkan. Namun ternyata penyajian prasmanan seperti itu cenderung menyulitkan pelanggan ketika akan mengambil menu makanan yang satu dengan yang lain apalagi jika kondisi sedang banyak pelanggan, karena menu makanan dijejerkan berdasarkan jenis makanan bukan berdasarkan menu yang sering dipilih oleh pelanggan, terlebih ketika rumah makan sedang ramai seperti saat makan siang kesulitan pelanggan dalam mengambil menu makanan tersebut akan menyebabkan antrian pelanggan.

Dengan adanya perkembangan teknologi seperti saat ini tentu saja sangat berpengaruh terhadap berbagai hal di kehidupan kita, seperti pada penelitian sebelumnya tentang penerapan algoritma apriori yaitu "Implementasi Data Mining dengan Metode Algoritma Apriori dalam Menentukan Pola Pembelian Obat", dimana pada penelitian ini menjelaskan tentang penerapan algoritma apriori dalam menentukan pola penjualan obat dengan mencari keterhubungan dari setiap obat dengan obat yang lain agar dapat mengetahui suatu susunan terbaik dalam penyusunan obat agar lebih mempermudah dalam pengambilan obat[2] .

Algoritma apriori bukan satu satunya algoritma yang bisa dipakai dalam aturan asosiasi, ada algoritma lain yang disebut algoritma hash based, namun algoritma apriori lebih banyak digunakan daripada algoritma hash based karena dalam proses menentukan aturan asosiasi algoritma apriori dapat lebih cepat dibandingkan dengan algoritma hash based, pada algoritma hash based menggunakan teknik penyaringan item yang tidak penting, ketika mencari alamat penyaring seringkali terjadi collison pada alamat dari tiap item sehingga pengulangan akan terus dilakukan sampai tidak terjadi collison, collison adalah tabrakan antara dua alamat penyaring, hal inilah yang menyebabkan algoritma hash based memiliki waktu yang lebih lama dibandingkan algoritma apriori [10].

Algoritma Apriori merupakan algoritma yang sangat terkenal untuk menemukan pola frekuensi tinggi, algoritma 
apriori ini termasuk jenis aturan asosiasi pada data mining. Pola frekuensi tinggi adalah pola-pola item di dalam suatu basis data yang memiliki frekuensi atau support. Pola frekuensi tinggi inilah yang digunakan untuk menyusun aturan assosiasi dan juga beberapa teknik data mining lainnya [11].

Berdasarkan latar belakang tersebut, yang menjadi tujuan penelitian kali ini yaitu menerapkan algoritma apriori menggunakan metode aturan asosiasi pada sebuah web agar ditemukan susunan yang lebih baik dalam penataan menu makanan di rumah makan prasmanan. Susunan tersebut diambil dari data-data transaksi yang sebelumnya sudah terjadi di rumah makan tersebut.

\section{LANDASAN TEORI}

\section{A. Rumah Makan Prasmanan}

Rumah makan prasmanan menjadi salah satu unit usaha yang banyak ditemukan di Indonesia, rumah makan prasmanan adalah, "suatu usaha yang menyediakan makanan sehari - hari dan disajikan secara prasmanan atau biasa juga disebut buffet, yakni makanan disajikan langsung di meja makan agar pelanggan dapat lebih leluasa mengambil menu makanan sesuai dengan kebutuhan mereka tanpa harus menunggu terlebih dahulu makanan disajikan [1].

\section{B. Data Transaksi}

Data adalah bahan keterangan dari suatu kejadian kejadian nyata atau fakta - fakta yang tidak acak yang dapat menunjukan jumlah, tindakan dan hal [4].

Jadi dari sebuah data kita dapat mengetahui suatu hal ataupun fakta dari suatu kejadian nyata yang telah terjadi.

Sedangkan pengertian transaksi adalah kegiatan yang dilakukan oleh seseorang yang dapat menimbulkan perubahan pada keuangan yang dipunyai baik bertambah ataupun berkurang [5].

Jadi data transaksi merupakan sekumpulan keterangan dari beberapa transaksi yang sudah dilakukan.

C. Association Rule (Aturan Asosiasi)

Pengertian Association rule menurut Vulandari adalah salah satu teknik dari data mining yang digunakan untuk mencari hubungan antar item dalam suatu dataset untuk menemukan aturan asosiasi antara suatu kombinasi item [7].

Association rule akan menemukan pola tertentu untuk mengasosiasikan atau menghubungkan data satu dengan data yang lain. Tahap pertama yang harus dilakukan dalam mencari Association rule dari suatu kumpulan data adalah mencari frequent itemset, yaitu sekumpulan item yang sering muncul secara bersamaan. Setelah kumpulan item yang sering muncul secara bersamaan ditemukan barulah mencari aturan keterkaitan yang memenuhi syarat yang telah ditentukan [9].

D. Algoritma Apriori

Algoritma Apriori merupakan algoritma yang sangat terkenal untuk menemukan pola frekuensi tinggi, Algoritma Apriori ini termasuk jenis aturan asosiasi pada data mining. Pola frekuensi tinggi adalah pola-pola item di dalam suatu basis data yang memiliki frekuensi atau support. Pola frekuensi tinggi inilah yang digunakan untuk menyusun aturan assosiatif dan juga beberapa teknik data mining lainnya [3].
Adapun alur pada pada algoritma apriori dapat dilihat pada Gambar 1 flowchart algoritma apriori [6].

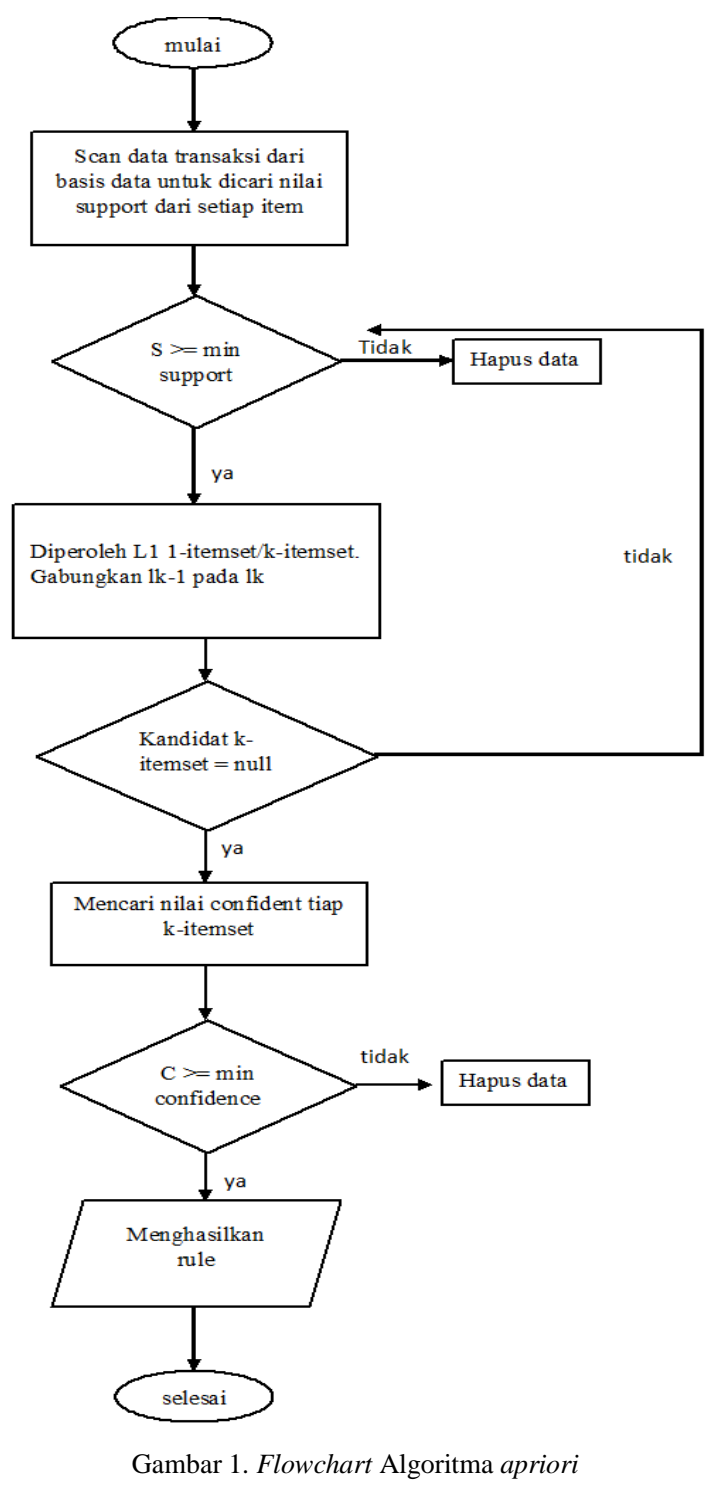

Dalam algoritma apriori pencarian suatu aturan asosiasi harus menggunakan parameter atau ukuran sehingga akan didapat aturan yang akurat, Parameter yang digunakan yaitu :

\section{Support}

Support merupakan suatu ukuran yang menunjukan seberapa besar tingkat dominasi dari suatu barang atau itemset dari keseluruhan transaksi yang ada. Untuk mengetahui nilai support menggunakan rumus:

$$
\text { Support }(A)=\frac{\text { jumlahtransaksimengandungA }}{\text { totaltransaksi }}
$$

Sedangkan untuk menghitung presentasi support dari suatu item menggunakan rumus: 


$$
\text { Support }(A)=\frac{\text { jumlahtransaksimengandungA }}{\text { totaltransaksi }} \times 100
$$

\section{Confidence}

Confidence adalah suatu ukuran yang menunjukan hubungan kondisional antar dua barang, misalnya seberapa sering produk D dibeli jika orang membeli produk C. Untuk menentukan suatu confidence menggunakan rumus:

$$
\text { Confidence }(A \rightarrow B)=\frac{\text { jumlahtransaksimengandung Adan } B}{\text { jumlahtransaksimengandung } A}
$$

Atau bisa juga menggunakan rumus :

$$
\text { Confidence }(A \rightarrow B)=\frac{\text { Support }(A . B)}{\text { Support }(A)}
$$

Sedangkan untuk menghitung persentase confidence bisa menggunakan rumus:

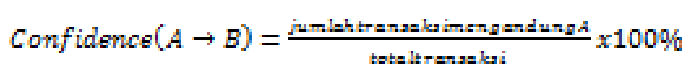

Terdapat 2 proses utama dalam algoritma apriori, yaitu :

1. Join (Penggabungan)

Dalam proses Join ini setiap item digabungkan dengan item yang lain sampai tidak dapat membentuk suatu kombinasi lagi.

\section{Pruning (Pemangkasan)}

Pada proses pruning ini hasil dari kombinasi item akan dipangkas berdasarkan minimum support yang telah ditentukan oleh pengguna.

\section{METODE PENELITIAN}

Metode yang dipakai dalam penelitian ini adalah aturan asosiasi dengan menggunakan algoritma apriori agar penyusunan menu makanan pada rumah makan prasmanan dapat tertata lebih baik sehingga memudahkan pelanggan ketika mengambil menu makanan. Aturan asosiasi merupakan salah satu metode dari teknik penggalian data atau data mining.

\section{A. Lokasi dan Objek Penelitian}

Penelitian dilakukan di rumah makan prasmanan, dengan objek penelitian mengenai tata letak menu makanan prasmanan. Dengan pengambil data sample transaksi di Rumah Makan ASGAR yang berlokasi di jalan SukabumiCianjur KM 11 Desa Sukalarang Kecamatan Sukalarang Kabupaten Sukabumi Jawa-Barat.

\section{B. Perumusan Masalah}

Permasalahan yang terjadi adalah pemilik rumah makan ataupun pelanggan kesulitan saat akan mengambil makanan lain karena posisi makanan satu dengan yang lain tidak berdekatan.

\section{Pengumpulan Data}

Pengumpulan data dilakukan dengan cara melakukan wawancara terdahap pemilik rumah makan.

\section{Perancangan Sistem}

Dalam perancangan sistem menggunakan algoritma apriori, yaitu suatu algoritma yang sering dipakai untuk menemukan frekuensi tertinggi dari item pada itemset untuk membentuk suatu aturan asosiasi.

E. Implementasi Sistem

Pada tahap ini dilakukan penerapan sistem kedalam sebuah web [8], dimana web ini akan menampilkan bagaimana proses penyusunan menu makanan prasmanan.

F. Pengujian

Tahapan ini dilakukan dengan cara menerapkan hasil susunan menu makanan. Kemudian melakukan wawancara dengan pemilik rumah makan.

\section{HASIL DAN PEMBAHASAN}

\section{A. Perumusan Masalah}

Masalah yang timbul yaitu tata letak menu makanan yang digunakan menyulitkan pemilik rumah makan ataupun pelanggan ketika akan mengambil menu makanan, sehingga pada penelitian ini akan dilakukan penerapan metode aturan asosiasi menggunakan algoritma untuk menyusun menu makanan prasmanan agar ditemukan susunan menu makanan yang lebih baik.

\section{B. Pengumpulan Data}

Pengumpulan data dilakukan dengan cara melakukan wawancara terhadap pemilik rumah makan sehingga didapatkan data - data sebagai berikut:

1. Nama - Nama Menu Makanan.

2. Data Sample Transaksi.

C. Perancangan Sistem

Menerapkan metode aturan asosiasi menggunakan algoritma apriori pada penelitian ini dengan tahapan algoritma apriori sebagai berikut:

1. Pembentukan Kandidat Itemset

Terdapat 18 item yang berupa menu makanan dan 250 sample transaksi yang didapat dari rumah makan asgar, adapaun menu makanan yang dimaksud dapat dilihat pada tabel I.

TABEL I

MENU MAKANAN

\begin{tabular}{|l|l|}
\hline Kode Menu & Nama Menu Makanan \\
\hline A1 & Ayam Goreng \\
\hline A2 & Ayam Bakar \\
\hline A3 & Ikan Nila Goreng \\
\hline A4 & Ikan Mas Goreng \\
\hline A5 & Ikan Kembung Goreng \\
\hline A6 & Ikan Bandeng Goreng \\
\hline A7 & Ikan Sepat Goreng \\
\hline A8 & Tumis Buncis \\
\hline A9 & Tumis Kangkung \\
\hline A10 & Tumis Tauge \\
\hline
\end{tabular}




\begin{tabular}{|l|l|}
\hline Kode Menu & Nama Menu Makanan \\
\hline A11 & Tumis Rebung \\
\hline A12 & Tumis Terong \\
\hline A13 & Balado Tongkol \\
\hline A14 & Balado Tempe Tahu \\
\hline A15 & Balado Telur \\
\hline A16 & Balado Ati Ampela \\
\hline A17 & Pesmol Ikan Mas \\
\hline A18 & Sayur Asem \\
\hline
\end{tabular}

Tabel I Menu Makanan merupakan itemset yang berupa menu-menu makanan yang terdapat di rumah makan asgar. Untuk data sample menggunakan traksaksi sebanyak 250 transaksi dari pengunjung rumah makan, pola transaksi penjualan menu makanan dapat dilihat pada Tabel II.

TABEL II

Pola Transaksi Penjualan Makanan

\begin{tabular}{|c|c|}
\hline Transaksi & Menu Makanan \\
\hline 1 & $\begin{array}{l}\text { Ayam Goreng, Tumis Kangkung,Tumis } \\
\text { Buncis }\end{array}$ \\
\hline 2 & Balado Telur,Tumis Buncis \\
\hline 3 & Ayam Bakar,Balado Telur,Tumis Tauge \\
\hline 4 & $\begin{array}{l}\text { Sayur Asem,Ikan Sepat Goreng,Tumis } \\
\text { Kangkung }\end{array}$ \\
\hline 5 & $\begin{array}{l}\text { Balado Tongkol,Tumis Terong,Tumis } \\
\text { Buncis }\end{array}$ \\
\hline 6 & Balado Ati Ampela,Tumis Tauge \\
\hline 7 & $\begin{array}{l}\text { Balado Telur,Tumis Kangkung,Tumis } \\
\text { Buncis }\end{array}$ \\
\hline 8 & $\begin{array}{l}\text { Tumis Rebung, Tumis Buncis,Balado } \\
\text { Tongkol }\end{array}$ \\
\hline 9 & Ayam Bakar,Tumis Buncis,Tumis Tauge \\
\hline 10 & $\begin{array}{l}\text { Tumis Buncis,Ayam Goreng, Balado } \\
\text { Telur }\end{array}$ \\
\hline 11 & $\begin{array}{l}\text { Ikan Sepat Goreng,Tumis Buncis, Tumis } \\
\text { Kangkung }\end{array}$ \\
\hline 12 & $\begin{array}{l}\text { Pesmol Ikan Mas,Balado Tempe } \\
\text { Tahu,Tumis Buncis }\end{array}$ \\
\hline 13 & $\begin{array}{l}\text { Balado Tongkol,Tumis Kangkung, } \\
\text { Tumis Rebung }\end{array}$ \\
\hline$\cdots$ & $\cdots$ \\
\hline 250 & Sayur Asem,Ikan Sepat Goreng \\
\hline
\end{tabular}

\section{Penghitungan Support}

Perhitungan support dilakukan untuk menentukan kandidat 1 itemset (C1), berikut ini merupakan perhitungan Support dari masing - masing item pada itemset berdasarkan Tabel Pola Transaksi Penjualan Makanan:

$$
\begin{array}{ll}
(A 1)=\frac{78}{250} \times 100 & (A 3)=\frac{27}{250} \times 100 \\
=31,20 & =10,80 \\
(A 2)=\frac{52}{250} \times 100 & (A 4)=\frac{35}{250} \times 100 \\
=20,80 & =14
\end{array}
$$

\begin{tabular}{|c|c|c|}
\hline Kode Menu & $\begin{array}{l}\text { Nama Menu } \\
\text { Makanan }\end{array}$ & Nilai Support \\
\hline A1 & Ayam Goreng & 31,20 \\
\hline $\mathrm{A} 2$ & Ayam Bakar & 20,80 \\
\hline$\overline{\mathrm{A} 3}$ & Ikan Nila Goreng & 10,80 \\
\hline$\overline{\mathrm{A} 4}$ & Ikan Mas Goreng & 14,00 \\
\hline A5 & $\begin{array}{l}\text { Ikan Kembung } \\
\text { Goreng }\end{array}$ & 2,80 \\
\hline A6 & $\begin{array}{l}\text { Ikan Bandeng } \\
\text { Goreng }\end{array}$ & 4,00 \\
\hline A7 & Ikan Sepat Goreng & 4,40 \\
\hline A8 & Tumis Buncis & 33,20 \\
\hline A9 & Tumis Kangkung & 25,20 \\
\hline A10 & Tumis Tauge & 21,60 \\
\hline A11 & Tumis Rebung & 21,60 \\
\hline A12 & Tumis Terong & 24,40 \\
\hline A13 & Balado Tongkol & 15,60 \\
\hline A14 & $\begin{array}{l}\text { Balado Tempe } \\
\text { Tahu }\end{array}$ & 7,60 \\
\hline A15 & Balado Telur & 10,40 \\
\hline A16 & $\begin{array}{l}\text { Balado Ati } \\
\text { Ampela }\end{array}$ & 14,00 \\
\hline A17 & Pesmol Ikan Mas & 15,20 \\
\hline A18 & Sayur Asem & 15,20 \\
\hline
\end{tabular}

Hasil perhitungan support dari masing - masing item di atas dapat dilihat pada Tabel III.

TABEL III

KANDIDAT 1-ITEMSET

\section{Proses Pemangkasan}

Proses pemangkasan dilihat dari hasil penghitungan support yang ada pada tabel hasil perhitungan support, prunning atau pemangkasan dilakukan bagi item yang nilai 
support nya tidak memenuhi minimum support yaitu 5 sehingga dapat dihasilkan kumpulan data nilai support dari masing - masing item atau biasa disebut dengan large 1 itemset (L1), untuk data large 1-itemset (L1) dapat dilihat pada tabel IV Large 1-Itemset.

\section{TABEL IV}

LARGE 1-ITEMSET

\begin{tabular}{|l|l|l|}
\hline Kode Menu & $\begin{array}{l}\text { Nama Menu } \\
\text { Makanan }\end{array}$ & Nilai Support \\
\hline A1 & Ayam Goreng & 31,20 \\
\hline A2 & Ayam Bakar & 20,80 \\
\hline A3 & Ikan Nila Goreng & 10,80 \\
\hline A4 & Ikan Mas Goreng & 14,00 \\
\hline A8 & Tumis Buncis & 33,20 \\
\hline A9 & Tumis Kangkung & 25,20 \\
\hline A10 & Tumis Tauge & 21,60 \\
\hline A11 & Tumis Rebung & 21,60 \\
\hline A12 & Tumis Terong & 24,40 \\
\hline A13 & Balado Tongkol & 15,60 \\
\hline A14 & $\begin{array}{l}\text { Balado Tempe } \\
\text { Tahu }\end{array}$ & 7,60 \\
\hline A15 & Balado Telur & 10,40 \\
\hline A16 & $\begin{array}{l}\text { Balado Ati } \\
\text { Ampela }\end{array}$ & 14,00 \\
\hline A17 & Pesmol Ikan Mas & 0,20 \\
\hline A18 & Sayur Asem & 0,14 \\
\hline
\end{tabular}

Bagi setiap item yang dihilangkan pada proses pemangkasan dapat memberikan informasi bagi pemilik rumah makan bahwa item atau menu makanan tersebut harus diganti dengan menu masakan yang lain.

4. Proses penggabungan

Proses join atau penggabungan dilakukan dengan cara menghitung support pada setiap item yang ada pada large 1itemset terhadap masing-masing item lain, yakni menhitung seberaoa sering 2 item muncul secara bersamaan untuk menghasilkan kandidat 2-itemset (C2), adapun contoh penghitungan sebagai berikut:

$$
\begin{array}{ll}
(A 1, A B)=\frac{21}{250} \times 100 & (A 2, A 8)=\frac{15}{250} \times 100 \\
=\mathbf{1 4} & =\mathbf{1 0 \%} \\
(A 1, A 9)=\frac{11}{250} \times 100 & (A 2, A 10)=\frac{17}{250} \times 100 \\
=\mathbf{7 , 3} & =\mathbf{1 1}
\end{array}
$$

Hasil penghitungan support untuk menentukan 2-

\begin{tabular}{|c|c|c|}
\hline Kode Menu & $\begin{array}{l}\text { Nama Menu } \\
\text { Makanan }\end{array}$ & Nilai Support \\
\hline $\mathrm{A} 1, \mathrm{~A} 8$ & $\begin{array}{l}\text { Ayam Goreng, } \\
\text { Tumis Buncis }\end{array}$ & 12,80 \\
\hline $\mathrm{A} 1, \mathrm{~A} 10$ & $\begin{array}{l}\text { Ayam Goreng, } \\
\text { Tumis Tauge }\end{array}$ & 7,60 \\
\hline $\mathrm{A} 1, \mathrm{~A} 12$ & $\begin{array}{l}\text { Ayam Bakar, } \\
\text { Tumis Buncis }\end{array}$ & 11,60 \\
\hline A1,A16 & $\begin{array}{l}\text { Ayam Bakar, } \\
\text { Balado Ati } \\
\text { Ampela }\end{array}$ & 5,60 \\
\hline $\mathrm{A} 1, \mathrm{~A} 11$ & $\begin{array}{l}\text { Ayam Bakar, } \\
\text { Tumis Rebung }\end{array}$ & 5,60 \\
\hline $\mathrm{A} 1, \mathrm{~A} 17$ & $\begin{array}{l}\text { Ayam Goreng, } \\
\text { Pesmol Ikan Mas }\end{array}$ & 5,60 \\
\hline A9,A8 & $\begin{array}{l}\text { Tumis Kangkung, } \\
\text { Tumis Buncis }\end{array}$ & 6,40 \\
\hline A9,A4 & $\begin{array}{l}\text { Tumis Kangkung, } \\
\text { Ikan Mas Goreng }\end{array}$ & 5,20 \\
\hline $\mathrm{A} 8, \mathrm{~A} 2$ & $\begin{array}{l}\text { Tumis Buncis, } \\
\text { Ayam Bakar }\end{array}$ & 9,60 \\
\hline $\mathrm{A} 8, \mathrm{~A} 10$ & $\begin{array}{l}\text { Tumis Buncis, } \\
\text { Tumis Tauge }\end{array}$ & 5,60 \\
\hline $\mathrm{A} 8, \mathrm{~A} 12$ & $\begin{array}{l}\text { Tumis Buncis, } \\
\text { Tumis Terong }\end{array}$ & 7,20 \\
\hline A8,A16 & $\begin{array}{l}\text { Tumis Buncis, } \\
\text { Balado Ati } \\
\text { Ampela }\end{array}$ & 5,20 \\
\hline $\mathrm{A} 2, \mathrm{~A} 10$ & $\begin{array}{l}\text { Ayam Bakar, } \\
\text { Tumis Tauge }\end{array}$ & 5,20 \\
\hline $\mathrm{A} 2, \mathrm{~A} 12$ & $\begin{array}{l}\text { Ayam Bakar } \\
\text { Tumis Terong }\end{array}$ & 6,80 \\
\hline
\end{tabular}
itemset(C2) di atas dapat dilihat pada tabel V Large 2-itemset.
TABEL $\mathrm{V}$

LARGE 2-ITEMSET

Proses iterasi atau perulangan dihentikan sampai terbentuk large 2-itemset, karena pada penelitian kali ini dibutuhkan hubungan dari masing - masing item hanya sampai 2 item saja untuk kemudian disusun.

\section{Pembentukan Aturan Asosiasi}

Pembentukan aturan asosiasi dilakukan dengan cara menghitung confident berdasarkan item yang ada pada tabel large 2-itemset, adapun penghitungan confident dari beberapa item sebagai berikut:

$$
\begin{array}{ll}
(A 1, A 8)=\frac{21}{78} \times 100 & (A 9, A 8)=\frac{17}{6 a} \times 100 \\
=41,03 & =25,40 \\
(A 1, A 10)=\frac{17}{78} \times 100 & (A 9, A 4)=\frac{16}{62} \times 100 \\
=24,36 & =20,63
\end{array}
$$


Setelah dilakukan penghitungan, kemudian dilakukan pemangkasan minimum confident yaitu dengan nilai minimun confident 5 karena ketika dilakukan percobaan dengan nilai minimum confident yang lebih besar pemangkasan terjadi terlalu banyak sehingga susunan menu makanan yang didapat cenderung terlalu sedikit, adapun hasil aturan asosiasi dapat dilihat pada Tabel VI.

TABEL VI

ATURAN ASOSIASI

\begin{tabular}{|l|l|l|}
\hline $\begin{array}{l}\text { Kode } \\
\text { Menu }\end{array}$ & $\begin{array}{l}\text { Nama Menu } \\
\text { Makanan }\end{array}$ & $\begin{array}{l}\text { Nilai } \\
\text { Confident }\end{array}$ \\
\hline A12,A1 & $\begin{array}{l}\text { Tumis Terong, Ayam } \\
\text { Goreng }\end{array}$ & 47,54 \\
\hline A2,A8 & $\begin{array}{l}\text { Ayam Bakar, Tumis } \\
\text { Buncis }\end{array}$ & 46.15 \\
\hline A1,A8 & $\begin{array}{l}\text { Ayam Goreng, Tumis } \\
\text { Buncis }\end{array}$ & 41,02 \\
\hline A16, A1 & $\begin{array}{l}\text { Balado Ati Ampela, } \\
\text { Ayam Goreng }\end{array}$ & 40 \\
\hline A8, A1 & $\begin{array}{l}\text { Tumis Buncis, Ayam } \\
\text { Goreng }\end{array}$ & 38,55 \\
\hline A4,A9 & $\begin{array}{l}\text { Ikan Mas Goreng, } \\
\text { Tumis Kangkung }\end{array}$ & 37,14 \\
\hline A17,A1 & $\begin{array}{l}\text { Pesmol Ikan Mas, } \\
\text { Ayam Goreng }\end{array}$ & 36,84 \\
\hline A10,A1 & $\begin{array}{l}\text { Tumis Tauge, Ayam } \\
\text { Goreng }\end{array}$ & 35,18 \\
\hline A11,A1 & $\begin{array}{l}\text { Tumis Rebung, } \\
\text { Ayam Goreng }\end{array}$ & 25,92 \\
\hline A9,A8 & $\begin{array}{l}\text { Tumis Kangkung, } \\
\text { Tumis Buncis }\end{array}$ & 25,39 \\
\hline
\end{tabular}

Susunan menu makanan dapat diatur sesuai dengan tabel aturan asosiasi di atas berdasarkan hasil urutan penghitungan confident yang terbesar hingga terkecil, susunan didapatkan dengan menguraikan kembali hasil dari Tabel VI. aturan asosiasi menjadi 1-itemset, untuk menu makanan yang tidak lolos pada penghitungan confident disimpan pada posisi terakhir dalam susunan menu makanan, sehingga dapat ditemukan susunan menu makanan prasmanan yang baru pada Tabel VII..

TABEL VII

Susunan MENu MaKanAN PRASMANAN

\begin{tabular}{|l|}
\hline Nama Menu Makanan \\
\hline Tumis Terong \\
\hline Ayam Goreng \\
\hline Ayam Bakar \\
\hline Tumis Buncis \\
\hline Balado Ati Ampela \\
\hline Ikan Mas Goreng \\
\hline Tumis Kangkung \\
\hline Pesmol Ikan Mas \\
\hline Tumis Tauge \\
\hline Tumis Rebung \\
\hline Balado Tongkol \\
\hline Balado Tempe Tahu \\
\hline Balado Telur \\
\hline Balado Ati Ampela \\
\hline Ikan Nila Goreng \\
\hline
\end{tabular}

\section{Implementasi sistem}

Metode algoritma apriori untuk menentukan susunan menu makanan prasmanan ini akan diterapkan pada sebuah aplikasi penyusunan menu makanan berbasis web, dengan tampilan sebagai berikut:

1. Tampilan Halaman Utama

Halaman utama yang merupakan tampilan utama pada web ini diperlihatkan pada Gambar 2. Tampilan Halaman Utama, pada halaman ini pengguna dapat memilih beberapa menu yang ada seperti menu masukan data, menu penyusunan menu makanan, menu hasil dan menu keluar.

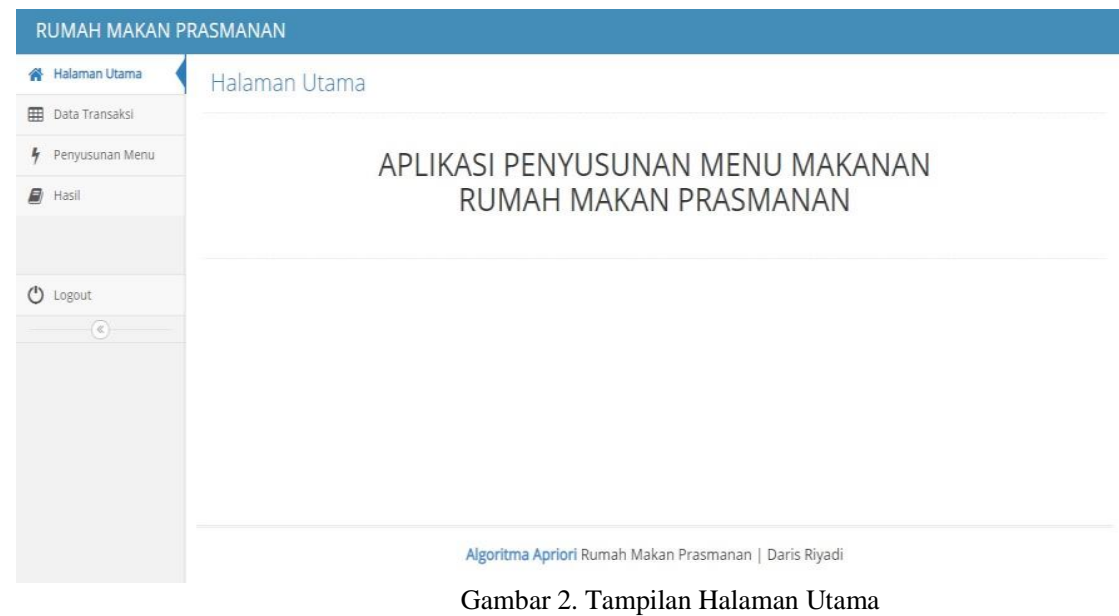


2. Tampilan Menu Masukan Data

Tampilan halaman menu masukan data dapat dilihat pada Gambar 3, pengguna dapat memasukkan data-data transaksi yang berupa file Microsoft Excel berformat .xls dengan struktur tabel memiliki 2 kolom yang berisi nomor transaksi dan nama menu makanan sebagai bahan untuk menentukan penyusunan menu makanan yang lebih baik.

\section{RUMAH MAKAN PRASMANAN}

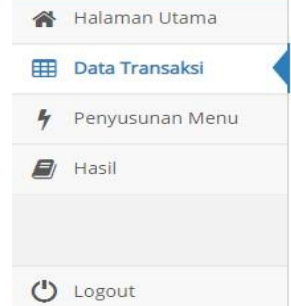

(1) Logout
Data Transaksi

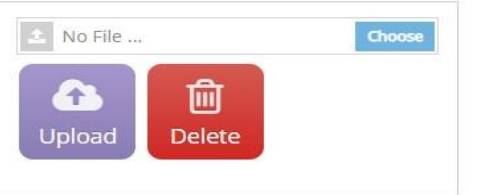

Gambar 3. Tampilan Halaman Masukan Data

3. Tampilan Penyusunan Menu

Menu penyusunan menu dapat dilihat pada Gambar 4, pengguna dapat menyusun menu makanan berdasarkan data- data transaksi yang sebelumnya sudah dimasukan kemudian dapat melihat hasil dari proses algortima apriori dan hasil penyusunan menu makanan.

\section{RUMAH MAKAN PRASMANAN}

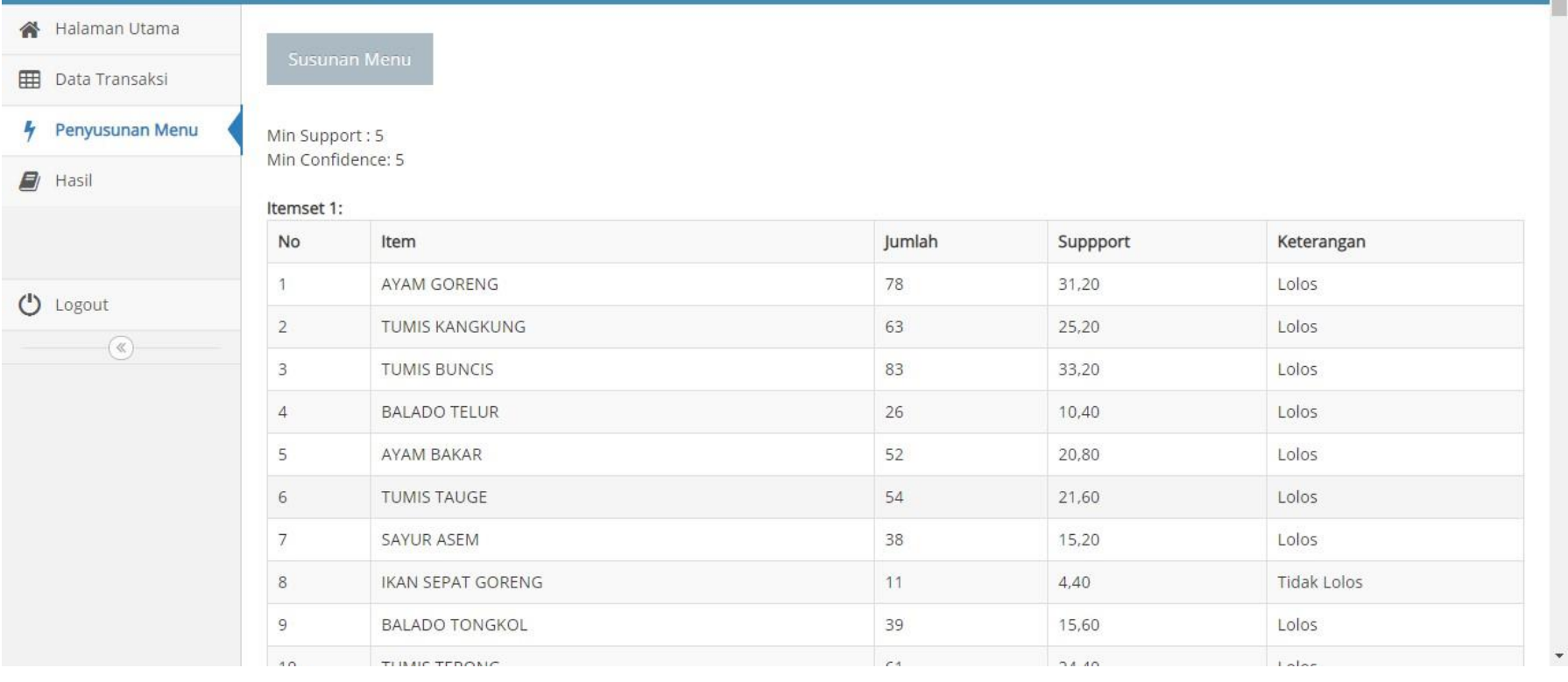




\section{Tampilan Hasil}

Menu hasil penyusunan diperlihatkan pada Gambar 5, pada halaman ini pengguna dapat melihat susunan menu yang dihasilkan dengan menggunakan algoritma apriori, susunan menu yang dihasilkan ini diurutkan berdasarkan nilai confident yang terbesar ke terkecil dari masing-masing item dengan item yang lain.

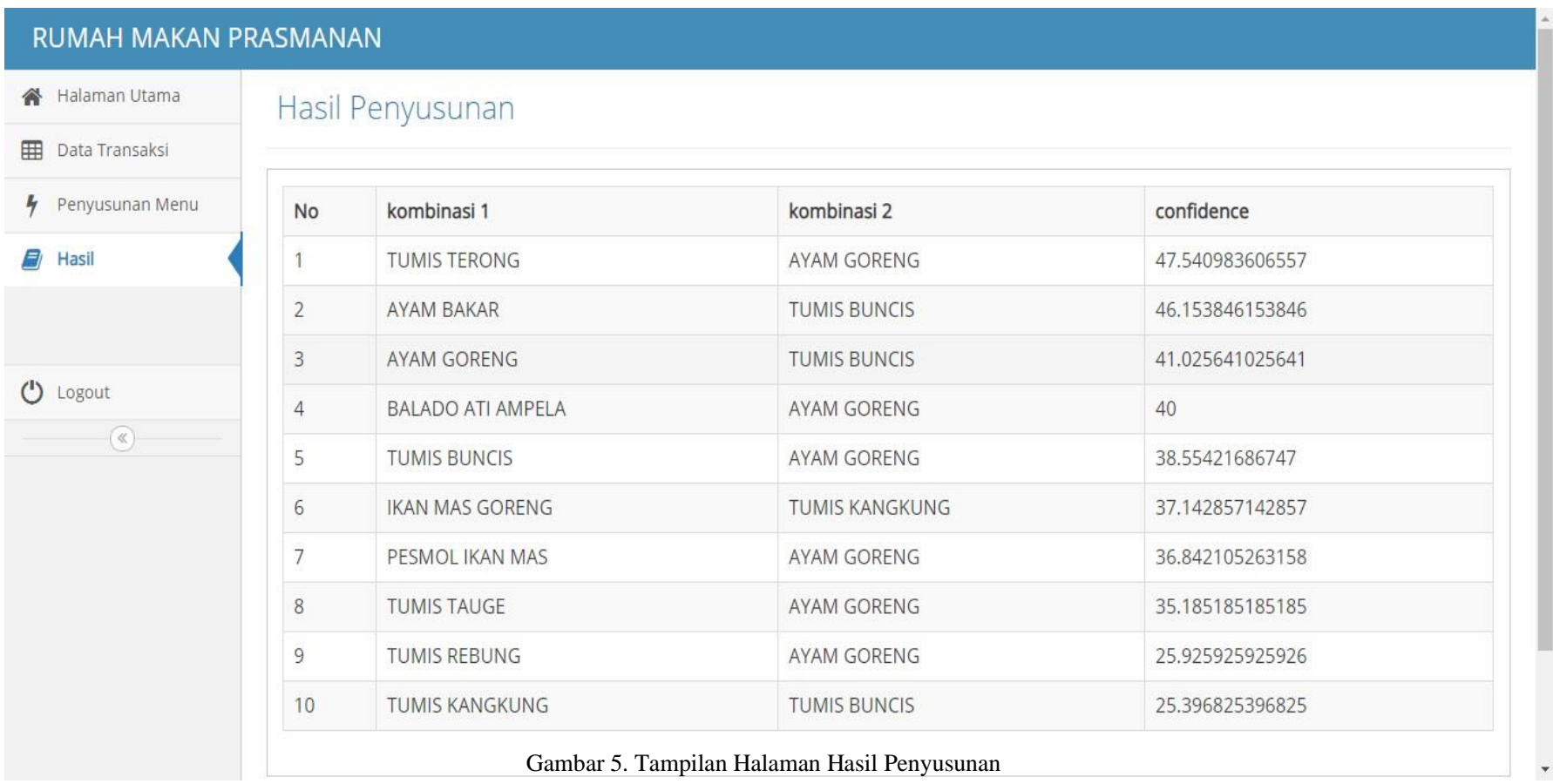

\section{E. Pengujian}

Pengujian dilakukan dengan cara menerapkan susunan menu makanan di rumah makan asgar berdasarkan hasil susunan dalam penelitian ini, kemudian dilakukan wawancara terhadap pemilik rumah makan dengan teks wawancara sebagai berikut:

Peneliti : Apakah pengambilan menu makanan satu dengan lainnya menjadi lebih mudah?

Pemilik RM : Ya

Peneliti : Apakah pengambilan menu makanan satu dengan lainnya menjadi lebih cepat

Pemilik RM : Ya

Peneliti

: Apakah antrian pengambilan menu makanan menjadi lebih pendek karena pengambilan menu makanan lebih cepat selesai?

Pemilik RM : Ya

\section{KESIMPULAN}

Berdasarkan hasil penelitian dan pengujian, sebelumnya menu makanan hanya disusun berdasarkan jenis makanan atau tempat yang tersedia pada meja menu makanan saja sehingga pelanggan atau pemilik rumah makan kesulitan ketika mengambil makanan satu dengan yang lainnya, namun setelah menggunakan susunan menu makanan dari hasil proses pencarian aturan asosiasi menggunakan algoritma apriori dapat ditemukan susunan menu makanan yang lebih baik karena menu makanan disusun sesuai dengan pola transaksi dari menu makanan yang terjadi sebelumnya, sehingga dapat lebih mempermudah ketika mengambil menu makanan karena menu makanan yang biasa diambil saling berdekatan satu sama lain.

Menu makanan disusun berdasarkan hasil nilai confident yang paling besar, seperti pada penelitian kali ini ditemukan nilai confident yang terbesar dari menu makanan ayam goreng adalah tumis terong dengan nilai confident sebesar 47,54 sehingga tumis terong ditaruh berdekatan dengan ayam goreng pada susunan menu makanan prasmanan.

Pada prosesnya algoritma apriori sangat tergantung dengan minimum support dan minimum confident yang dipakai, semakin kecil minimum support dan minimum confident maka proses pencarian menu makanan akan semakin lama namun susunan yang dihasilkan akan lebih kuat begitupun sebaliknya.

Selain nilai minimum support dan minimum confident, jumlah data yang diolah juga mempengaruhi pada proses 
pencarian aturan asosiasi, karena semakin banyak data yang diolah akan memerlukan waktu yang lebih lama namun aturan asosiai yang dihasilkan akan lebih baik, terlebih dalam melakukan proses pencarian menu makanan kedepannya diharuskan menggunakan data transaksi yang paling baru karena pola transaksi yang ada dapat berubah.

\section{DAFTAR PUSTAKA}

[1] Zakaria, O., \& Kusrini,'Implementasi Data Mining Terhadap Penyusunan Layout Makanan pada Rumah Makan Padang Murah Meriah." Seminar Nasional Teknologi Informasi Dan Multimedia, 2013, pp. 1-6.

[2] Yanto, R., \& Khoiriah, R,"Implementasi Data Mining dengan Metode Algoritma Apriori dalam Menentukan Pola Pembelian Obat." Citec Journal, vol. 2, no. 2, pp. 102-113, 2015.

[3] Arifah Destiyati, O. S., \& Aribowo, E."Analisis Perbandingan Algoritma Apriori Dan Algoritma Hash Based Pada Market Basket Analysis Di Apotek Uad.” Jurnal Sarjana Teknik Informatika, vol. 3, no. 1 , pp. 1-10, 2015
[4] Sutanta, E., \& Yogyakarta, T. A. Sistem Basis Data. Yogyakarta: Graha Ilmu, 2014.

[5] B. Questribilia. (2019) Kenali Pengertian Transaksi Beserta Jenisjenisnya on Akuntansi [Online]. Tersedia: https://www.jojonomic.com/blog/pengertian-transaksi/

[6] Sophia, D., \& Yuniar, 1."Menggunakan algoritma apriori pada data." Jurnal Informatika dan Komputer, vol. 22, no. 1, pp. 44-56, 2017.

[7] Vulandari, R. T, Data mining teori dan aplikasi rapidminer, Surakarta: penerbit gava media, 2017.

[8] Yeni Kustiyahningsih, D. R. A. Pemrograman Basis Data Berbasis Web Menggunakan PHP \& MySQL, Yogyakarta, 2011.

[9] Nursikuwagus, A., \& Hartono, T.'Implementasi Algoritma Apriori Untuk Analisis Penjualan Dengan Berbasis Web." Simetris: Jurnal Teknik Mesin, Elektro Dan Ilmu Komputer, vol. 7, no. 2, pp. 701, 2016.

[10] Ramadhan, F.”Implementasi Algoritma Hash Based Terhadap Aturan Asosiasi untuk Menentukan Frequent Itemset Study Kasus Rumah Makan Seafood Kita." Seminar Nasional Teknologi Informasi Dan Multimedia, 2017, pp. 97-102.

[11] Listriani, D., Setyaningrum, A. H., \& Eka, F."Penerapan Metode Asosiasi Menggunakan Algoritma Apriori Pada Aplikasi Analisa Pola Belanja Konsumen (Studi Kasus Toko Buku Gramedia Bintaro)." Jurnal Teknik Informatika, vol. 9, no. 2, pp. 120-127, 2018. 